\title{
Operating Auxiliaries: A Review
}

\author{
Dr.Manish Bhalla ${ }^{1}$, Dr.Pramod Yadav ${ }^{2}$, Dr.Maryam Siddiqui ${ }^{3}$, \\ Dr.Aditi Bhalla ${ }^{4}$ \\ ${ }^{I}$ (Public Health Dentistry, K.D.Dental College \&Hospital/Agra University, India) \\ ${ }^{2}$ (Public Health Dentistry, K.D.Dental College \&Hospital/Agra University, India) \\ ${ }^{3}$ (Pedodontics, K.D.Dental College \&Hospital/Agra University, India) \\ ${ }^{4}$ (K.D.Dental College \&Hospital/Agra University, India)
}

\begin{abstract}
A review of the literature on operating dental auxiliaries and their utilization in the dental workforce is presented, and their role is examined in the light of broader issues relating to changing disease patterns and service delivery. A strategy for adopting a team approach in the delivery of dental services is mentioned, which would necessitate the dentist taking on the role of team leader and maintaining responsibility for overall treatment planning and quality assurance. Dental auxiliaries could provide basic preventive and restorative dental services, allowing dentists to concentrate on providing more complex high technology treatment. Implications for the future training of dental auxiliaries are presented.
\end{abstract}

Key words: Dental auxiliaries, dental manpower, operating auxiliary.

\section{Introduction}

"For someone to have good general health and well being they must also have good oral health". Professor Greg Aymour

The world of health care changes rapidly. As we enter the twenty-first century, health care professionals will encounter more challenges than ever before, but with the challenges comes opportunity. Job prospects for dental assistants have never been better. The Bureau of Labour Statistics expects employment to grow much faster than the average for all occupations through the year 2014. Population growth and greater retention of natural teeth will fuel demands for dental services. As the health care industry requires more work to be done by dentists, the dental auxiliary will be more valuable and needed than even before. Dental auxiliary is a generic term for all personnel who assist the dentist in treating patient. In Britain, they have been known as "dental ancillaries, the word auxiliary means, being helpful, subsidiary; whereas ancillary means subservient subordinate. ${ }^{1}$

The expert committee on auxiliary dental personnel of the World Health Organization (WHO) met in Geneva from the $30^{\text {th }}$ of June to the $6^{\text {th }}$ of July, 1958. The committee made recommendations to those nations that might be seeking to expand their dental health care system. ${ }^{2}$ In 1967 there was an inter- regional seminar on the training and utilization of dental personnel in New Delhi and in 1968 a survey of legislation on auxiliaries, including dental auxiliaries, was published ${ }^{2}$. (WHO 1968)WHO activities in this area have included the development of curriculum outlines for use in training courses for dental auxiliaries, the establishment of training programmes in Senegal and the provision of technical assistance to many countries. ${ }^{3}$ Specialization in dentistry has increased the need for auxiliaries known as operating dental auxiliaries began in 1913 in the United States of America, 1921 in New Zealand. ${ }^{4}$ Dental auxiliary personnel have become integral part of modern dental practice in United States. A survey of dental practice in 1977 revealed that only $6 \%$ of dentists in solo practice did not employ any auxiliaries, while 33\% employed four or more auxiliary personnel's, around $91 \%$ of all dentists practicing alone in United States employed a dental assistant while $45 \%$ employed a full or part time dental hygienist.(Furstman 1981). ${ }^{5}$

The Nuffield Report on Dental Education shows clearly that the profession generally was against auxiliaries but formal and informal reports to the committee showed their value as members of the dental team. Nuffield indicated that New Cross should be closed and their training stopped. London Hospital then started to train therapists, finishing up with dual therapist-hygienist qualifications after 27 months. ${ }^{6}$ In a densely populated country like India, where more than $70 \%$ of population lives in rural areas. Hence, it is a paramount consideration to train additional personnel to reach the unreached. ${ }^{7}$

\section{Non-operating auxiliary}

\section{Definitions 8, 9}

Clinical: This is a person who assists the professional (dentist) in his clinical work but does not carry out any independent procedures in the oral cavity.

Laboratory: This is a person who assists the professional by carrying out certain technical laboratory procedures. 


\section{Operating auxiliary}

This is a person who, not being a professional is permitted to carry out certain treatment procedures in the mouth under the direction and supervision of a professional.

$>$ Dental auxiliary is a person who is given responsibility by a dentist so that he or she can help the dentist render dental care, but who is not qualified with a dental degree.

$>$ "Dental auxiliary" means a person who may perform dental supportive procedures authorized by the provisions of these regulations under the specified supervision of a licensed dentist.

> "Dental assistant" means an unlicensed person who may perform basic supportive dental procedures specified by these regulations under the supervision of a licensed dentist.

> "Registered Dental Assistant" or RDA means a licensed person who may perform all procedures authorized by the provisions of these regulations and in addition may be performed by a dental assistant and registered dental assistant, under the designated supervision of a licensed dentist.

> "Registered Dental Hygienist" or RDH means a licensed person who may perform all procedures authorized by the provisions of these regulations and in addition may be performed by a dental assistant and registered dental assistant, under the designated supervision of a licensed dentist.

\section{Classification}

In 1959 WHO expert committee reported on auxiliaries dental personnel and described two basic types ${ }^{2}$ :

1. Dental Licentiate.

2. Dental Aides.

World Health Organization (WHO 1968) ${ }^{9}$ :

Based on the nature of duties they perform, auxiliaries can be classified into two categories: Non-operating auxiliary

a. Clinical -This is the person who assists the professional in his clinical work but does not carry out any independent procedure in oral cavity

b. Laboratory-This is a person who assists the professional by carrying out certain technical laboratory procedure

\section{Operating auxiliary}

This is a person who, not being a professional is permitted to carry out certain treatment procedures in the mouth under the direction and supervision of a professional.

\section{Revised classification':}

Non- operating

- Dental surgery assistant

- Dental secretary/receptionist

- Dental laboratory technician

- Dental health educator

\section{Operating}

- School dental nurse

- Dental therapist

- Dental hygienist

- Expanded functions operating dental auxiliaries

\section{Classification based on length of training ${ }^{10}$ :}

Jeboda (1982) suggested a classification based on that adopted by WHO (1968) in New Delhi. He recognized the following categories:

1. Long term trained ( 2 to 4 years)

2. Short term trained (4 to 6 months)

\section{FDI classification based on STRATA - Training concepts ${ }^{11}$}

According to the technical report of the commission on dental education and practice adopted by the general assembly of the FDI at its meeting in Vienna, in October 1982, dental auxiliaries may be grouped into various vertical strata and horizontal levels according to their degree of training and education. The strata levels are based on a series of integrated courses of education and training in which knowledge and skill gained in one course serve as the foundation for progress to a higher level course in the series. The system proposed allows direct entrance to the advanced strata of those with higher general education standards. The term dental auxiliary 
may include the chairside assistant, dental nurse, dental health educator, hygienist, school dental therapist, dental therapist, extended function (duty) dental assistant (E.F.D.A.)

\section{Stratum Level:}

$\mathrm{T}$ his represents the dental assistant who undergoes practical training within the dental office and for whom there is no formal training course certificate available.

Table $1^{11}$ : The core subjects in strata-training programme

\begin{tabular}{|c|c|c|c|c|}
\hline General studies & $\begin{array}{l}\text { Biological } \\
\text { sciences }\end{array}$ & Dental science & $\begin{array}{l}\text { Dental assisting } \\
\text { and } \\
\text { clinical practice }\end{array}$ & $\begin{array}{l}\text { Principles of dental } \\
\text { radiography }\end{array}$ \\
\hline Communication Psychology & $\begin{array}{c}\text { Anatomy, } \\
\text { Histology, } \\
\text { Physiology, } \\
\text { Microbiology, } \\
\text { Pathology, } \\
\text { Diet and nutrition, } \\
\text { Hygiene }\end{array}$ & $\begin{array}{c}\text { Dental Materials, Oral } \\
\text { Anatomy and } \\
\text { Physiology, Oral } \\
\text { Pathology, Dental } \\
\text { Pharmacology and } \\
\text { Therapeutics }\end{array}$ & $\begin{array}{c}\text { Principles of } \\
\text { practice } \\
\text { management and } \\
\text { chairside assisting, } \\
\text { Legal and ethical } \\
\text { aspects of dentistry, } \\
\text { First aid and dental } \\
\text { emergencies }\end{array}$ & $\begin{array}{l}\text { Development, handling } \\
\text { filing of X-ray films, } \\
\text { Principles of radiography, } \\
\text { Radiation hygiene }\end{array}$ \\
\hline
\end{tabular}

Table $2^{11}$ : Admission requirements and training period by stratum and level for various auxiliary

\begin{tabular}{|c|c|c|c|}
\hline & Designation & Admission requirements & Training period \\
\hline Stratum 1 Level I & $\begin{array}{l}\text { Dental Assistant: } \\
\text { no formal training }\end{array}$ & $\begin{array}{l}\text { 9-10 years formal education } \\
\text { minimum age } 15-16 \text { years }\end{array}$ & In service experience \\
\hline Level II & $\begin{array}{l}\text { Trained Dental } \\
\text { Assistant with } \\
\text { education; clinical } \\
\text { training; certificate }\end{array}$ & $\begin{array}{l}\text { 9-10 years education } \\
\text { minimum age } 15-16 \text { years }\end{array}$ & $\begin{array}{l}\text { 3-6 hours per week } \\
\text { for } 1 \text { year and in } \\
\text { service experience }\end{array}$ \\
\hline $\begin{array}{c}\text { Level III } \\
\text { Stratum } 2 \text { Level I }\end{array}$ & $\begin{array}{l}\text { Oral Health Educator } \\
\text { EFDA- multiple certificate in } \\
\text { special skills }\end{array}$ & $\begin{array}{c}\text { Stratum } 1 \text { Level II certificate } \\
\text { Stratum } 1 \text { Levels II or III } \\
\text { certificate }\end{array}$ & $\begin{array}{l}\text { 4-6 weeks full time } \\
\text { 8-10 weeks full time }\end{array}$ \\
\hline Stratum 3 Level I & Dental Hygienist & $\begin{array}{l}\text { (a) direct } 12 \text { years education } \\
\text { (b) Stratum: Stratum } 2 \\
\text { Certificate }\end{array}$ & $\begin{array}{c}\text { (a) } 4 \text { semesters- } 2 \\
2 \text { semesters-1 year } \\
\text { (b) } 20 \text { weeks full time } 1 \\
\text { semester }\end{array}$ \\
\hline Stratum 4 Level I & School Dental Therapist & $\begin{array}{l}\text { (a) Direct: Matriculation } \\
\text { (b) Stratum: Stratum } 3 \\
\text { certificate }\end{array}$ & $\begin{array}{l}\text { (a) } 4 \text { semesters-2 years } \\
\text { (b) } 3 \text { semesters }\end{array}$ \\
\hline Level II & Tutor Therapist & Stratum 4 Level I certificate & 1 semester \\
\hline
\end{tabular}

\section{Operating Dental Auxiliaries in India}

Poised to become the world's most populous nation by 2040, India face daunting challenges-huge burdens of disease, lack of needed medical care in many regions, and a dearth of public health professionals. India has about 272 dental institutions producing 25000-30000 B.D.S graduates every year. In 2004 the dentist to population ratio in India was 1:30000. But with a significant geographic imbalance among dental colleges there has been a great variation in the dentist to population ratio in rural and urban areas.

The dental auxillary present in India are dental hygienist, laboratory technician and dental surgery assistants. They have to undergo a training of 2 year in institutes which have been recognized by Ministry of Health; Government of India and certificate courses recognized by Dental Council of India.

Dental auxiliary courses in India: In India there are only two approved courses for dental auxiliary training programs:

A. Dental Mechanics (2 years course after $12^{\text {th }}$ pass)

B. Dental Hygienist (2 years course after $12^{\text {th }}$ pass) ${ }^{9}$

\section{History of School Dental Nurse}

\section{School Dental Nurse ${ }^{1,8}$}

This auxiliary, is permitted to diagnose dental disease and to plan and carry out certain specified preventive and treatment measures, including some operative procedures in the treatment of dental caries and periodontal disease in defined groups of people, usually school children. The Dental Nurse Scheme was established in Wellington, New Zealand in 1921 due to the extensive dental disease found in army recruits during World War I (1914-1918). The man who influenced its formation was T.A. Hunter, a founder of the New Zealand Dental Association and a pioneer in the establishment of a dental School in New Zealand. The name of the school where they were trained was "The Dominion Training School for Dental Nurses". 
Each school which takes more than 100 children has its own dental clinic. When a school dental nurse is assigned to a school, she is accepted as a member of the staff in the same way as are the teachers. ${ }^{8}$

New Zealand School Dental Nurses are employed in a number of other countries, many of which have started their own training schemes. By 1970, there were at least 15 other countries and jurisdictions that had adopted similar plans. In Britain, the first operating auxiliaries based on the New Zealand school dental nurse model graduated in 1962. They were generally known as, 'New Cross Auxiliaries, because the one training school is located in the New Cross area of South London. In Saskatchewan, a Canadian province and the only place in North America where school dental nurse other than a dentist may legally drill and fill the teeth. They are less expensive to train than dentists and their salaries are similar to those of physical therapists and school teachers. $^{8}$

\section{History of Dental Therapist}

\section{The Dental Therapist ${ }^{1,8}$}

This is a person who is permitted to carry out to the prescription of a supervising dentist, certain specified preventive and treatment measures including the preparation of cavities and restoration of teeth.

In the United Kingdom, dental dressers (as the equivalents of therapists were called) came into being because of a shortage of dentists to work in the school dental service. The auxiliaries based on the New Zealand type graduated in 1962 from the Erstwhile training school, which was in the New Cross area of London. Hence, they were known as "New Cross Auxiliaries". In 1979, in the U.K., the name auxiliary was changed to therapist. In Australia, therapists the personnel categories who are derivatives of the New Zealand Dental Nurse model have been in service since 1966. They are like New Zealand type school dental nurses but their role is quite different, as they are not permitted to diagnose and plan dental care.

\section{Duties of a Dental Therapist}

The functions of a therapist vary. Their training includes clinical caries diagnosis, technique of cavity preparation in deciduous and permanent teeth, material handling and restorative skills, vital pulpotomies under rubber dam in deciduous teeth and extraction of deciduous teeth under local anesthesia. They have little training in interpretation of X-rays. They often take radiographs at the request of the supervising dentist. They are not trained to provide endodontic care. In Western Australia, if used in mobile clinics to service remote areas, they may not treat dental trauma cases, but may provide emergency first aid.

\section{Qualification of Dental Therapist ${ }^{14}$}

The length of the diploma course is about 27 months. Some dental schools offer part time courses for dental hygienists wishing to qualify as dental therapists.

Subjects studied include preventive dentistry, dental health education, and dental pathology, simple restorative procedures for both deciduous and permanent teeth, the extraction of deciduous teeth, radiography and pharmacology.

\section{Income of a Dental Therapist ${ }^{15}$}

There is great variation in earnings for dental therapists from those at the entry level to those well experienced. According to the Saskatchewan Job Futures, dental therapists are well paid. Full time workers are paid an Average of $\$ 40,000$.

\section{Expanded Functions Operative Dental Auxiliary: (EFODA) ${ }^{1,8}$}

An EFODA is a dental assistant or a dental hygienist in some cases, who had received further training in duties related to the direct treatment of patients, though still working under the direct supervision of a dentist. The utilization of EFODA's were given importance during the 1960's at the time when a critical shortage of dental personnel was seen as imminent. ${ }^{1}$

\section{Duties of EFODA ${ }^{1,8}$}

EFODA undertake reversible procedures, that is which could be either corrected or redone without undue harm to the patient's health. They do not prepare cavities or make decision as to pulp protection after caries has been excavated, but work alongside the dentist and take over routine restorative procedures, as soon as the cavity preparation and base have been completed.

The first large-scale service applications of the expanded duty principle were made in Philadelphia. They were called "Technotherapist". ${ }^{1,8}$ 


\section{Qualification of Expanded Functions Dental Auxillary}

The Expanded Functions Dental Auxiliary (EFDA) Certificate is designed to prepare graduates for positions in private practice dental offices, dental clinics; federal, state and municipal health departments; and correctional institutions Depending on the type of work required, training period of EFODA is adjusted accordingly. He/she works in close co-ordination and supervision of dentist. As a result of this it is found that the dentist's productivity increased by $61.5 \% .{ }^{18}$

\section{New Operating Auxiliary Types ${ }^{1,20}$}

The expert Committee on auxiliary dental personnel of the W.H.O. (1959) has suggested new type of Dental auxiliaries:

\section{The dental licentiate}

2. The dental aide

These new auxiliaries are particularly useful in some countries, having acute dentist shortage, with no facilities for training dentists. ${ }^{20}$

\section{Role of Operative Dental Auxiliary in Four Handed Dentistry Four handed dentistry:}

The term four handed dentistry is given to the art of seating both the dentist and the dental assistant in such a way that both are within easy reach of patient's mouth. The patient is in fully supine position. The assistant will hand the instruments to the dentist. It will also perform additional tasks such as retraction or aspiration. ${ }^{1}$

The performance of four-handed dentistry requires certain basic elements to be effective elements which are a mixture of mechanical, technical. \& attitudinal factors that must he combined if the concept is to succeed.

- Positive Team Attitude ${ }^{19}$

- Favorable Work Environment

- Proper Positioning of Patient and Operating Team

- Simplified Instrumentation

- Standardized Operating Procedures

- Efficient Instrument Delivery

- Effective Oral Evacuation and Debridement

- Proper Time Management.

\section{Conclusion}

\section{According To Revised Classification Various Operating Auxiliaries are:}

- School dental nurse

- Dental therapist

- Dental hygienist

- Expanded functions operating dental auxiliaries

India (2004) had one dentist for 10000 persons in urban areas \& 2.5 lakh persons in rural areas. Almost $3 / 4$ of total numbers of dentist are clustered in urban areas which houses only one-fourth of the country's population. India needs a longer positive approach in the creating and expanding dental auxiliaries systems to meet the demands. The dental auxiliary present in India are dental hygienist, laboratory technician and dental surgery assistants, which have been recognized by Ministry of Health; Government of India and certificate courses recognized by Dental Council of India.

\section{References}

[1]. Soben Peter. Essentials of preventive and community dentistry; fourth edition; 2011:412-420.

[2]. WHO, Technical report series no. 163: 1959; expert committee on auxiliary dental personnel: 3-5.

[3]. WHO, The training and utilization of dental hygienists and dental assistants; American Dental Association: 1967.

[4]. Dental auxiliaries.www.en.wikipedia.org/wiki/.dental auxiliary, accessed on 15-1-13.

[5]. Dental Assisting Word of Mouth Careers in the Dental Profession; American Dental Association: 2006.

[6]. Dental auxiliary Careers in the Dental Profession Word of Mouth Dental Laboratory Technology; American Dental Association: 1998.

[7]. S.S. Hiremath. Textbook of Preventive and Community Dentistry; 2011:223- 25

[8]. Geoffery L. Slack, Brian A.Burt. An Introduction to community dental health,2nd edition;1981: 201-219.

[9]. C.M Marya. A text book of public health dentistry, first edition; 2011: 212- 216.

[10]. WHO, Inter-regional seminar on the training and utilization of dental personnel in developing countries. New Delhi, 1967; Geneva: WHO.

[11]. FDI, Classification of dental auxiliary personnel based on strata- training concepts, International Dental Journal 1983; 33: 308-312. 
[12]. Dental hygienist Hygienist Training programs approved by Dental Council of India (i.e. Government of India)http://www.medindia.net/ education/dental_colleges.asp , accessed on 4-1-13.

[13]. School dental nurse. http://en. wikipedia.org/wiki/_ Dental_nurse\# Qualifications, accessed on 5-3-13.

[14]. Dental therapist. http://www.nhscareers.nhs.uk/explore-by-career/dental-team/careers-in-the-dental-team/dental-therapist,accessed on 04-3-13.

[15]. Dental therapist http://www.health.gov.sk.ca/dental-therapist, accessed on 04-03-13.

[16]. Dental hygienist. http://www.ada. org/sections / education And Careers/ pdfs /brochure_dentalhygiene.pdf, accessed on 5-3-13.

[17]. Dental hygienist.https:// national careersservice. direct. gov.uk/advice/planning/ jobprofiles/Pages/dentalhygienist.aspx, accessed on $5-3-13$.

[18]. Expanded function dental auxiliary. https://www.owens.edu/academic_dept/health_tech/efda / index.html, accessed on 2-3-13.

[19]. Cara M. Miyasaki-Ching. A Textbook of Essentials of Clinical Dental Assisting, $5^{\text {th }}$ edition; 1997:211-12.

[20]. Dunning Mores James. A text book on Principle of Dental Public Health, $4^{\text {th }}$ edition; 1986:452-53.

[21]. Kennedy DP. New Zealand's Dental Auxillary Programme. World Health Organization Chronicle 1951; 43:65-69.

[22]. Coomer OB. Role of auxiliary Personnel in augmenting services of the dentist.Journal of American Dental Association1956; 52: $442-448$.

[23]. Hammons P.E, Jamision H.C. Expanded functions for dental auxiliaries. Journal of American Dental Associaton 1967; 75:882 886.

[24]. Walter J. Pelton, George A Overstreet, Olice H. Embry, James B. Dilworth. Economic implications of adding one therapist to a practice. Journal of American Dental Association 1973; 86: 1301 - 1309.

[25]. Romcke R.G, Lewis D. W. Use of expanded function dental - hygienists in the prince Edward Island man power study. Journal of Canadian Dental Association 1973; 4: $247-262$.

[26]. Abramowits Joseph, Lawrence E. Berg. A four year study of the utilization of dental assistant with expanded functions. Journal of American Dental Association 1973; 87: 623 - 634

[27]. H. H. Tan, H. G. Van Gemert. Time utilization, productivity and costs of solo and extended duty auxiliary dental practice. Community Dentistry and Oral Epidemiology 1977; 5:151-155.

[28]. Judith K. Barr, Charles E. Barr. The structure of the dental profession and the use of auxiliaries in Latin America. Social Science \& Medicine. Part A: Medical Psychology \& Medical Sociology 1980; 14(2):107-111.

[29]. Michael K. Chapko, Marilyn Bergner, Barbara Beach, Kathy Green, Peter Milgrom, and Nicholas Skalabrin. Development of a measure of job satisfaction for dentists and dental auxiliaries. Community Dentistry and Oral Epidemiology 1986; 14:76-79.

[30]. David Locker, David Burman, Dan Otchere. Work related stress and its predictors among Canadian dental assistants. Community Dentistry and Oral Epidemiology 1989; 17: 263-266.

[31]. Riordan PJ, Espelid I, Tveit AB. Radiographic interpretation and treatment decisions among dental therapists and dentists in western Australia. Community Dentistry and Oral Epidemiology 1991; 19: $268-271$.

[32]. Axelsson P, Rolandsson M, Bejerner B. How Swedish dental hygienists apply their training program in the field. Community Dentistry and Oral Epidemiology 1993; 21: 297 - 302.

[33]. David Locker. Work stress, and emotional well-being among Canadian dental assistants. Community Dentistry and Oral Epidemiology 1996; 24: 133-137.

[34]. Ohrn K, Crossner C.G, Borgesson I, Taube A. Accuracy of dental hygienists in diagnosing dental decay. Community Dentistry and Oral Epidemiology 1996; 24:182-186.

[35]. Benjamin Peretz, Kalpan Ruth, Stabholtz Ayala. The influence of a patient management course to dental hygiene students on the dental anxiety of their patients. Journal of Dental Education 1997; 61 (4): $368-378$.

[36]. Laura Baltutis, Michael Morgan. The changing role of dental auxiliaries: A review: Australian Dental Journal 1997; 43:354-8.

[37]. Cavington Patricia, Bonnie J Craig, Dip D.H. Survey of the information Seeking patterns of dental hygienist. Journal of Dental Education 1998; 62 (8): 573 - 577.

[38]. De Jongh A, Southhard Marlis E.A. Anxiety about dental hygienist treatment. Community Dentistry and Oral Epidemiology1998; 21: 91-95.

[39]. Stabholz Ayala, Jerusalem Jonathan Mann. Periodontal health and the role of dental hygienists. International Dental Journal 1998; 48: 50-55.

[40]. Hawley G.M, Wainwright-Stringer Y, Carven R, Blinkhorn A. S. An investigation into the use of a dental hygienist in school screening. Community Dental Health 1999; 16: 232 -235.

[41]. Hillman D G.A survey of hygienists qualifying from the Liverpool School of Dental Hygiene1977-1998. British Dental Journal 2000; 188 (3): $150-153$

[42]. Baltutis L.M, Gussy M.G, Morgan M. V. The role of the dental hygienist in the public health sector; an Australian perspective. International Dental Journal 2000; 50 (1): $29-35$.

[43]. John J. H, Thomas D, Richard D, Evans C. Regulating dental nursing in the UK. British Dental Journal 2002; 193 : 207 - 209.

[44]. Eaton K. A, Newman H.N, Widstrom E.A. survey of dental hygienist numbers in Canada, the European Economic area, Japan and the United States of America. British Dental Journal 2003; 195(10): 595-598.

[45]. Shobha Tondon. Challenges to the oral health workforce in India. Journal of Dental Education 2004; 68:28-33.

[46]. Ross M.K, Ibbeton R.J, Rennie J.S. Educational needs and employment status of Scottish dental hygienists. British Dental Journal 2005; 198(2):105-109.

[47]. Brown. Timothy T, Tracy L Finlayson, Richard M Scheffler. How to measure shortages of dental hygienists and dental assistants? Journal of American Dental Association 2007; 138: 94-100.

[48]. Anthony S Kravitz, Elizabeth T Treasure Cardiff. Utilization of dental auxiliaries attitudinal review from six developed countries. International Dental Journal 2007; 5: 267-273.

[49]. Gagnon Fabien, Catellier Pierre, Gauthier Isabelle Areteau, Tremblay Elisabeth Simard, Saucer Marianne Lepages, Robert Nina Paradis, Michel, Lavalliere Andre. Compliance with Fluoride Supplements Provided by a Dental Hygienist in Homes of LowIncome Parents of preschool Children in Quebec. American Association of Public Health Denti stry 2007; 67 (1): 60-63. 